\title{
Corte Interamericana de Direitos Humanos: A Construção do Direito ao Acesso à Justiça
}

\begin{abstract}
Cristina Figueiredo Terezo Ribeiro
Doutora em Direito pela Universidade Federal do Pará. Professora do Programa de Pós-Graduação em Direito da Ufpa. Docente Pesquisadora da Clínica de Direitos Humanos da Amazônia. Visiting Scholar do Washington College of Law, American University. Projetos de Pesquisa nos Sistemas Internacionais de Proteção dos Direitos Humanos, Grupos Vulnerabilizados e Direitos Econômicos, Sociais e Culturais.cfterezo@hotmail.com

\section{Manoel Maurício Ramos Neto}

Advogado. Assessor jurídico do Ministério Público do Estado do Pará. Voluntário da Clínica de Direitos Humanos da Amazônia. mau. mauricionetto@hotmail.com
\end{abstract}

O presente artigo versa sobre o entendimento da Corte Interamericana de Direitos Humanos a respeito do direito de acesso à justiça, considerando que este, apesar de não possuir previsão expressa na Convenção Americana de Direitos Humanos, tem sua existência declarada pelo Tribunal supracitado em sua jurisprudência, cuja base normativa relaciona-se à interpretação conjunta dos artigos $8^{\circ}$ e 25 em conexão com os artigos 10.1 e 2으, todos constantes no tratado internacional aludido. Destarte, busca-se analisar, mediante pesquisa jurisprudencial dos principais precedentes, a construção jurisprudencial empreendida pelo Tribunal Interamericano a respeito da matéria, analisando-se o contexto fático dos casos e a hermenêutica empregada para a apreciação das referidas demandas. Ademais, investiga-se os principais aspectos, de fato e de direito, referentes ao reconhecimento do direito em comento como uma norma jus cogens de Direito Internacional e os respectivos reflexos no âmbito do Sistema Interamericano de Direitos Humanos, a partir de uma discussão doutrinária.

Palavras-chave: Direitos humanos. Direito de acesso à justiça. Corte Interamericana de Direitos Humanos. Convenção Americana de Direitos Humanos.

INTER-AMERICAN COURT OF HUMAN RIGHTS: CONSTRUCTION OF THE RIGHT TO ACCESS TO JUSTICE

\section{ABSTRACT}

This article deals with the understanding of the Inter-American Court of Human Rights concerning the right of access to justice, whereas this, despite it has no express provision in the American Convention on Human Rights, its existence was declared by the Court in its jurisprudence, whose normative basis related to the joint interpre-

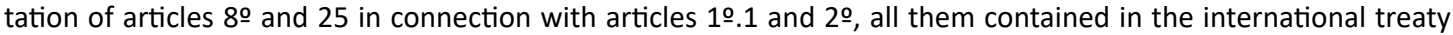
mentioned. Thus, it seeks to analyze, by jurisprudential research, the jurisprudential construction undertaken by the Inter-American Court on this matter, analyzing the factual context of the cases and hermeneutics used for the assessment of such claims. Furthermore, the major is investigated aspects, based on fact and law, relating to the recognition of the right under discussion of jus cogens norm of international law and their reflections in the Inter-American Human Rights System, from a doctrinal discussion.

Keywords: Human rights. Right to access to justice. Inter-American Court of Human Rights. American Convention on Human Rights.

\section{SUMÁRIO}

1 Introdução. 20 direito de acesso à justiça Lato Sensu. 2.10 direito de acesso à justiça como integrante do domínio do Jus Cogens. 3 Conclusão. 4 Referências. 


\section{INTRODUÇÃO}

O direito de acesso à justiça não se encontra previsto expressamente na Convenção Americana de Direitos Humanos (CADH), mas sua existência foi declarada em diversas sentenças proferidas pela Corte Interamericana de Direitos Humanos (CorteIDH), fruto de construção jurisprudencial, fundamentada essencialmente nos artigos 8 e 25 relacionados aos

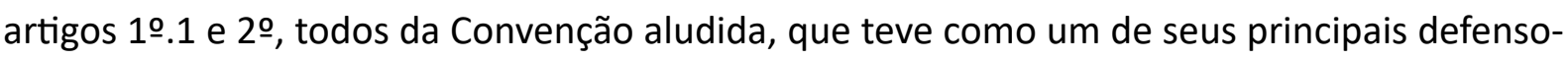
res o ex-juiz desse Tribunal, Antônio Augusto Cançado Trindade, o que se pode constatar, especialmente, em seus votos em separados nas sentenças dos casos Massacre de Pueblo Belo vs. Colômbia e Ximenes Lopes vs. Brasil, ambos de 2006.

Vale destacar que a jurisprudência a respeito dos direitos às garantias judiciais e à proteção judicial, tutelados, respectivamente, pelos artigos $8^{0^{1}}$ e $25^{2}$ da CADH, é muito ampla, haja vista que, na maioria dos casos julgados pela CortelDH, os artigos supracitados são objeto de análise geralmente com relação à negação do direito de acesso à justiça das vítimas, mediante a obstacularização da devida reparação, julgamento e sanção dos eventuais responsáveis por violações de outros Direitos Humanos, tais como, inter alia, vida, integridade pessoal, liberdade pessoal, tutelados pelos artigos 4으, 5ㅇ e 7으 da CADH, nessa ordem.

Diante disto, o presente artigo - tendo em vista a limitação do objeto que se investiga não intenta analisar toda a jurisprudência da CorteIDH sobre os artigos 8 o e 25 da CADH, mas promover um estudo a respeito dos casos paradigmáticos, os quais fixaram os precedentes da Corte de São José e possibilitam a compreensão sobre o conteúdo e os principais aspectos sobre os direitos às garantias judiciais e à proteção judicial, formando a base do direito de acesso à justiça e a declaração deste como integrante do domínio do jus cogens.

\footnotetext{
Artículo 8. Garantías Judiciales - 1. Toda persona tiene derecho a ser oída, con las debidas garantías y dentro de un plazo razonable, por un juez o tribunal competente, independiente e imparcial, establecido con anterioridad por la ley, en la sustanciación de cualquier acusación penal formulada contra ella, o para la determinación de sus derechos y obligaciones de orden civil, laboral, fiscal o de cualquier otro carácter. 2 . Toda persona inculpada de delito tiene derecho a que se presuma su inocencia mientras no se establezca legalmente su culpabilidad. Durante el proceso, toda persona tiene derecho, en plena igualdad, a las siguientes garantías mínimas: a) derecho del inculpado de ser asistido gratuitamente por el traductor o intérprete, si no comprende o no habla el idioma del juzgado o tribunal; b) comunicación previa y detallada al inculpado de la acusación formulada; c) concesión al inculpado del tiempo y de los medios adecuados para la preparación de su defensa; d) derecho del inculpado de defenderse personalmente o de ser asistido por un defensor de su elección y de comunicarse libre y privadamente con su defensor; e) derecho irrenunciable de ser asistido por un defensor proporcionado por el Estado, remunerado o no según la legislación interna, si el inculpado no se defendiere por sí mismo ni nombrare defensor dentro del plazo establecido por la ley; f) derecho de la defensa de interrogar a los testigos presentes en el tribunal y de obtener la comparecencia, como testigos o peritos, de otras personas que puedan arrojar luz sobre los hechos; g) derecho a no ser obligado a declarar contra sí mismo ni a declararse culpable, y h) derecho de recurrir del fallo ante juez o tribunal superior. 3. La confesión del inculpado solamente es válida si es hecha sin coacción de ninguna naturaleza. 4. El inculpado absuelto por una sentencia firme no podrá ser sometido a nuevo juicio por los mismos hechos. 5. El proceso penal debe ser público, salvo en lo que sea necesario para preservar los intereses de la justicia.

2 Artículo 25. Protección Judicial - 1. Toda persona tiene derecho a un recurso sencillo y rápido o a cualquier otro recurso efectivo ante los jueces o tribunales competentes, que la ampare contra actos que violen sus derechos fundamentales reconocidos por la Constitución, la ley o la presente Convención, aun cuando tal violación sea cometida por personas que actúen en ejercicio de sus funciones oficiales. 2. Los Estados Partes se comprometen: a) a garantizar que la autoridad competente prevista por el sistema legal del Estado decidirá sobre los derechos de toda persona que interponga tal recurso; $b$ ) a desarrollar las posibilidades de recurso judicial, y c) a garantizar el cumplimiento, por las autoridades competentes, de toda decisión en que se haya estimado procedente el recurso.
} 
Por meio da presente pesquisa jurisprudencial de precedentes, foi feita a análise do contexto fático dos casos, bem como das técnicas de interpretação empregadas pelo Tribunal Interamericano, tendo como objetivo identificar os fundamentos para formulação do que a referida Corte convencionou denominar de direito de acesso à justiça e sua classificação como normas de jus cogens de Direito Internacional, problematizando, ao final, sobre seus reflexos no âmbito do Sistema Interamericano de Direitos Humanos a partir de uma discussão doutrinária.

\section{DIREITO DE ACESSO À JUSTIÇA LATO SENSU}

$\mathrm{O}$ artigo XVIII ${ }^{3}$ da Declaração Americana dos Direitos e Deveres do Homem estabelece o direito à justiça, o qual, conforme explicitado anteriormente, estipula que toda pessoa tem o direito de recorrer aos tribunais para fazer respeitar seus direitos, assim como deve contar com processos simples e breves que garantam proteção judicial contra atos de autoridades que violem, em seu prejuízo, quaisquer dos direitos fundamentais consagrados constitucionalmente.

O direito de acesso à justiça, entretanto, não está previsto expressamente na CADH, apesar de que o reconhecimento do mesmo encontra-se em inúmeras decisões da Corte Interamericana (BLANCO, 2012, p. 103), sendo, dessa forma, fruto de construção jurisprudencial desenvolvida a partir da interpretação conjunta das obrigações contidas nos artigos 8 e 25 do tratado aludido, relacionados às obrigações gerais estabelecidas nos artigos 1‥1 e 2ㅇ desse mesmo tratado internacional de Direitos Humanos.

No caso Velásquez Rodríguez vs. Honduras (OEA, 1987), apesar dos artigos 8o e 25 não serem objetos de análise direta pela CorteIDH, na sentença de exceções preliminares, de 26 de junho de 1987, consignou-se que a regra do esgotamento de recursos internos gera para os Estados o dever de disponibilizar recursos judiciais efetivos às vítimas de violações de Direitos Humanos nos termos do artigo 25, que devem estar fundamentados pelas regras do devido processo legal, estabelecidas no artigo 8‥1, haja vista a obrigação geral dos Estados de garantir o livre e pleno exercício dos direitos reconhecidos pela CADH a toda pessoa sob sua jurisdição estipulada pelo artigo 10.1 (OEA, 1987).

Em que pese a relação entre os artigos 8o, 25 e 1‥1, apontada no caso Velásquez Rodríguez, ainda não havia uma decisão no Tribunal Interamericano que analisasse a violação conjunta desses dispositivos no mérito de uma demanda. A esse respeito, em seu voto dissidente no caso Caballero Delgado e Santana vs. Colômbia (OEA, 1997a, § 7-9), Cançado Trindade sustentou uma interpretação integradora dos artigos 8ㅇ , 25, 1ㅇ e 2ㅇ da CADH e, ao contrário da CortelDH, concluiu pela violação dos quatro dispositivos aludidos relacionados entre si.

Esse mesmo entendimento fora postulado pelo ex-juiz da CortelDH supracitado em seu voto dissidente na resolução acerca do pedido de revisão de sentença do caso Genie Lacayo vs. Nicarágua (OEA, 1997b, § 28), na qual analisou o conteúdo material e o alcance do artigo

Artículo XVIII. Toda persona puede ocurrir a los tribunales para hacer valer sus derechos. Asimismo debe disponer de un procedimiento sencillo y breve por el cual la justicia lo ampare contra actos de la autoridad que violen, en perjuicio suyo, alguno de los derechos fundamentales consagrados constitucionalmente. 
25 em relação com os artigos 8ㅇ, 10.1 e 2ㅇ, todos da CADH, e, defendendo entendimento diferente do adotado pela Corte naquele caso, postulou a ocorrência de uma violação dos dispositivos "tomados em conjunto".

Dois meses após a resolução citada anteriormente, em 3 de novembro de 1997, a CorteIDH proferiu a sentença de mérito do caso Castillo Páez vs. Peru (OEA, 1997c, § 83), a qual representa uma importante decisão para essa construção jurisprudencial a respeito do direito de acesso à justiça, haja vista que reconheceu o vínculo existente entre os artigos 25 e 1‥1, apesar de não ter incluído nessa análise o artigo 8‥

Nesse mesmo sentido, o Tribunal concluiu que o Estado peruano violou o direito à proteção judicial, relacionado com o dever de respeito e garantia, em razão da ineficácia do recurso de habeas corpus para proteger a vida e a liberdade de Ernesto Rafael Castillo Páez, o qual, após ser submetido à custódia da Polícia do Peru e ter seu paradeiro ocultado por esta, fora considerado vítima de desaparecimento forçado pela CortelDH.

A interpretação conjunta dos artigos 8 e e 25 somente fora realizada pela CorteIDH na decisão de mérito do caso Durand e Ugarte vs. Peru (OEA, 2000, § 130), que também versava sobre o desaparecimento forçado, provocado por agentes estatais, durante a ditadura peruana, empreendido contra Nolberto Durand Ugarte e Gabriel Pablo Ugarte Rivera. Nessa sentença, o Tribunal Interamericano consignou que o artigo 8ㅇ, em conexão com o artigo 25, protegiam o direito dos familiares das vítimas do desaparecimento à investigação efetiva, processo dos acusados, punição dos eventuais responsáveis e reparação pelos danos e prejuízos sofridos.

Essa linha jurisprudencial, mantida em inúmeras decisões da CortelDH, contribuiu para a consagração do direito de acesso à justiça, cujo conteúdo fora analisado pelo Tribunal Interamericano na sentença de mérito do caso Cantos vs. Argentina (OEA, 2002, §50-52), na qual a Corte estabeleceu que os artigos 8 e 25 da CADH consagram o direito de acesso à justiça na medida em que o primeiro dispositivo supracitado estipula que os Estados não devem criar obstáculos de qualquer ordem que impeçam ou dificultem que as pessoas busquem pela proteção de seus direitos no Poder Judiciário, enquanto o segundo traz a obrigação positiva do Estado de conceder a todas as pessoas sob sua jurisdição recursos judiciais efetivos contra atos violatórios de seus direitos (OEA, 2001b, § 48).

A partir da evolução da jurisprudência do Tribunal de São José, tem-se um precedente no qual se verifica que os dispositivos supracitados convergem para o reconhecimento da necessidade de se proteger os direitos das pessoas contra os abusos do poder público, de modo que toda e qualquer transgressão de direitos possa ser submetida à apreciação do Poder Judiciário no plano doméstico dos Estados (OEA, 2006a, § 17).

Na sentença de mérito do caso Massacre de Mapiripán vs. Colômbia (OEA, 2005, § 195), a CortelDH destacou a vinculação entre os artigos 8 ㅇ e 25, em relação com o artigo 1‥1, todos da $\mathrm{CADH}$, no sentido de que os Estados devem garantir recursos efetivos, substanciados e conformidade com as regras do devido processo legal, considerando a obrigação geral de respeito e de garantia. Destaca-se que esse se tornou o precedente no qual a CortelDH declarou a violação dos artigos 8 o e 25 em conexão com o artigo 1‥1, em que pese o liame entre esses dispositivos já ter sido apontado desde a sentença de exceções preliminares do caso Velásquez Rodríguez, conforme assinalado anteriormente. 
No caso Barrios Alto vs. Peru (OEA, 2001a, § 42), a CortelDH considerou que as leis de anistia adotadas pelo Estado peruano impediram que os familiares das vítimas, ou os sobreviventes do massacre de Barrios Alto, ${ }^{4}$ fossem ouvidos por um juiz, conforme estipulados pelo artigo 8 ..1. Assim, violaram o direito à proteção judicial consagrado no artigo 25 , bem como impediram a investigação, julgamento, sanção dos responsáveis e o devido esclarecimento dos fatos, em desrespeito ao artigo 10.1. Ademais, a adoção das leis de autoanistias incompatíveis com a CADH representa o descumprimento da obrigação de adequar o direito interno contida no artigo 2 desse mesmo tratado internacional.

Assim, com base nas obrigações gerais estabelecidas nos artigos 1‥1 e 20 da CADH, os Estado devem adotar todas as medidas necessárias para que nenhuma pessoa sob sua jurisdição, seja privada da proteção judicial e do exercício do direito a um recurso simples e eficaz, nos termos dos artigos 8o e 25 da Convenção Americana. Desse modo, as leis de autoanistia, que deixam as vítimas indefesas e perpetuam a impunidade, bem como impedem a identificação dos indivíduos responsáveis por violações aos Direitos Humanos, na medida em que criam obstáculos à investigação e ao acesso à justiça e impedem as vítimas e seus familiares de obterem o conhecimento da verdade e recebimento da reparação correspondente, violam os direitos previstos nos dispositivos supracitados, relacionados com os artigos 10.1 e 2ㅇ, todos da CADH (OEA, 2001a, § 43).

Essa linha jurisprudencial foi mantida pela Corte Interamericana em diversos outros casos que tratavam sobre leis de anistia como obstáculos ao direito de acesso à justiça das vítimas de violações a Direitos Humanos, dentre os quais destacam-se, La Cantuta vs. Peru (OEA, 2006b); Almonacid Arellano e outros vs. Chile (OEA, 2006c); Gomes Lund e outros (Guerrilha do Araguaia) vs. Brasil (OEA, 2010); Gelman vs. Uruguai (OEA, 2011); Massacres de El Mozote e arredores vs. El Salvador (OEA, 2012), entre outros.

Assim, com base em seus precedentes, a CorteIDH firma sua jurisprudência no sentido de que as vítimas de violações aos Direitos Humanos possuem o direito de contar com amplas possibilidades de serem ouvidas e atuarem nos respectivos processos, seja em busca de esclarecimentos dos fatos e punição dos responsáveis, seja em busca de uma devida reparação. Esse direito não decorre apenas da $\mathrm{CADH}$, mas também de normas imperativas de Direito Internacional (OEA, 2010, § 139), o que gera obrigações erga omnes para os Estados para adotarem todas as medidas necessárias e não deixar impunes tais violações, exercendo sua jurisdição doméstica para aplicação de seu direito interno e do Direito Internacional, visando à proteção das vítimas (OEA, 2006b, § 160).

A respeito desse entendimento jurisprudencial firmado pela CortelDH, Cançado Trindade (2003b, p. 13) defende que os artigos 8 o e 25 da CADH correspondem ao acesso à justiça lato sensu, o qual se caracteriza, em suma, como o direito à pronta prestação jurisdicional e obtenção de justiça, consubstanciado na indissociabilidade que há entre esses dispositivos.

\footnotetext{
O massacre de Barrios Alto ocorreu em 3 de novembro de 1991, quando seis indivíduos do grupo Colina, composto por integrantes do Exército peruano, invadiram um edifício onde estava ocorrendo uma festa que tinha como objetivo arrecadar fundos para a reforma do referido edifício, que ficava localizado em um bairro conhecido como Barrios Alto. Após a invasão do local, os militares obrigaram as vítimas a deitarem-se ao chão, em seguida empreenderam disparos por cerca de 2 minutos, o que resultou na morte de 15 pessoas e em 4 vítimas gravemente feridas. Cf. OEA. Organização dos Estados Americanos. CortelDH. Caso Barrios Altos vs. Peru. Sentença de Mérito, de 14 de março de 2001a. § 2.
} 
Tal direito não se reduz ao acesso formal, stricto sensu, às instâncias judiciais (tanto interna, como internacional), mas compreende o direito à prestação jurisdicional e encontra-se subjacente às disposições inter-relacionadas da Convenção Americana (como os artigos 25 e 8), além de permear o direito interno dos Estados partes. $O$ direito de acesso à justiça, dotado de conteúdo jurídico próprio, significa, lato sensu, o direito de obter justiça. Configura, assim, em suma, como o direito à própria realização da justiça. ${ }^{5}$

Manuel Ventura Robles (2007, p. 348) conceitua o direito em questão como a possibilidade de toda pessoa ter acesso aos mecanismos e sistemas previstos para a resolução de conflitos e reivindicação dos direitos protegidos, dos quais é titular, independentemente de sua condição econômica ou de outra natureza. Trata-se da possibilidade de poder recorrer aos mecanismos estabelecidos pelos ordenamentos jurídicos nacionais e internacionais para se buscar a resolução de uma controvérsia ou esclarecimento de um fato.

Nesse viés, Robles (2007, p. 348) defende que o acesso às instâncias judiciais, sejam nacionais ou internacionais, demandam a necessidade do melhoramento e otimização da administração da justiça, haja vista ser nesta seara que se define a vigência dos direitos fundamentais nas sociedades contemporâneas, quando se verifica se as liberdades e as garantias enunciadas nos diferentes instrumentos de Direito Internacional possuem aplicação real em âmbitos interno e internacional de proteção.

Mario Melgar Adalid (1998, p. 1.037-1.038), por sua vez, alerta para a função do processo como mecanismo de acesso à justiça e a redefinição do mesmo após a Segunda Guerra Mundial, no sentido de que o direito de acesso à justiça aponta, necessariamente, a existência de um "Estado Social de Direito", onde se pratique a justiça, o que pressupõe que as regras processuais não apenas devem regular um procedimento estabelecido e engessado pelos códigos adjetivos das distintas matérias jurídicas, tais como civil, penal, ou administrativa, na medida em que o processo, verdadeiramente, converteu-se em um dos instrumentos essenciais para o alcance do direito de acesso à justiça.

Um dos componentes principais do direito de acesso à justiça refere-se à possibilidade de demandar diretamente perante as autoridades judiciais competentes, mediante um recurso efetivo e célere, bem como o direito de ser ouvido por juízes ou tribunais, independentes e imparciais, tanto em âmbito nacional quanto internacional, nos termos dos artigos 8 e 25 da CADH (OEA, 2006a, § 61-62). Trata-se do "verdadeiro direito ao direito", o qual gera para os Estados a obrigação de, inter alia, garantir um ordenamento jurídico que efetivamente salvaguarde os direitos fundamentais das pessoas (TRINDADE, 2002, p. 524) e a devida prestação jurisdicional, que abrange as garantias do devido processo legal, assim como a fiel execução das decisões judiciais (OEA, 2006a, § 28).

\footnotetext{
"Tal derecho no se reduce al acceso formal, stricto sensu, a la instancia judicial (tanto interna como internacional), sino comprende, además, el derecho a la prestación jurisdiccional, y encuéntrase subyacente a disposiciones interrelacionadas de la Convención Americana (como los artículos 25 y 8), además de permear el derecho interno de los Estados Partes. El derecho de acceso a la justicia, dotado de contenido jurídico propio, significa, lato sensu, el derecho a obtener justicia. Configúrase, así, en suma, como el derecho a la propia realización de la justicia". In: OEA. Organização dos Estados Americanos. CortelDH. Caso Massacre de Pueblo Bello vs. Colômbia. Voto separado do Juiz Antônio Augusto Cançado Trindade. Sentença de 31 de janeiro de 2006a. Série C, N. 140, §§61-62; TRINDADE, Antônio Augusto Cançado. El Derecho de Acceso a la Justicia Internacional y las Condiciones para su Realización en el Sistema Interamericano de Protección de los Derechos Humanos. 37 Revista del Instituto Interamericano de Derechos Humanos, 2003a, p. 53.
} 


\section{Humanos}

Democracia

Nesse viés, faz-se mister destacar, ainda, as relações entre os dispositivos da CADH supracitados e a regra de esgotamento dos recursos internos. A esse respeito, Héctor Ledesma (2007, p. 41-42) assinala que a necessidade de esgotamento dos recursos pelos peticionários antes de demandarem perante as instâncias internacionais, implica uma obrigação paralela para os Estados, qual seja, de garantir a existência de um aparato judicial que funcione e que contemple recursos apropriados para proteger as pessoas no exercício de seus Direitos Humanos, uma vez que a inexistência de recursos efetivos deixa as vítimas sem meios de defesa, justificando-se, então, a proteção internacional, em caráter subsidiário.

[...] Os Estados têm a responsabilidade de consagrar normativamente e de assegurar a devida aplicação dos recursos efetivos e as garantias do devido processo legal pelas autoridades competentes que amparem todas as pessoas sob sua jurisdição contra atos que violem seus direitos fundamentais, ou que envolvam a determinação de direitos ou obrigações estatais. O propósito desses recursos é que, mediante eles, os Estados cumpram efetivamente com seu dever de proteger e garantir os Direitos Humanos consagrados na Convenção, a qual requer que as sentenças dos tribunais nacionais sejam devidamente acatadas e executadas. ${ }^{6}$

Segundo Cançado Trindade (OEA, 2006a, § 15), o sentido atual dos artigos 8o e 25 da $\mathrm{CADH}$, na compreensão da CorteIDH, é fruto de uma construção jurisprudencial que deve ser observada como parâmetro de interpretação desses dois dispositivos, os quais, apesar de sua autonomia e conteúdo material próprio, devem ser analisados considerando a necessidade de uma proteção mais eficaz à luz da indivisibilidade dos Direitos Humanos e o princípio do direito intertemporal.

De acordo com esse entendimento, os artigos 8 e e 25 da CADH não devem ser considerados apenas com base numa visão estática presa à formulação original dos dispositivos, mas devem ser relacionados considerando seu enfoque de proteção, buscando-se conferir maior eficácia à tutela dos Direitos Humanos (OEA, 2006a, § 15). Desse modo, o direito à proteção judicial está intimamente vinculado à obrigação geral de respeito e garantia (artigo 10.1 da $\mathrm{CADH}$ ), bem como ao direito às garantias do devido processo legal (artigo 8o da CADH), na medida em que assegura o acesso à justiça. Esse vínculo entre os referidos artigos protegem o exercício dos direitos das pessoas no plano interno dos Estados (OEA, 2006a, § 20).

\footnotetext{
“[...] Estados tienen la responsabilidad de consagrar normativamente y de asegurar la debida aplicación de los recursos efectivos y las garantías del debido proceso legal ante las autoridades competentes que amparen a todas las personas bajo su jurisdicción contra actos que violen sus derechos fundamentales, o que conlleven a la determinación de los derechos y obligaciones de éstas. El propósito de estos recursos es que, mediante ellos, el Estado haga efectivo su deber de proteger y garantizar los derechos consagrados en la Convención, lo cual requiere que las sentencias de los tribunales nacionales sean debidamente acatadas y ejecutadas". In: LEDESMA, 2007. p. 45.
} 


\subsection{O direito de acesso à justiça como integrante do domínio do Jus Cogens}

O Direito Internacional dos Direitos Humanos não está limitado aos direitos enumerados nos tratados internacionais, haja vista que também compreende os direitos que passaram a fazer parte do Direito Internacional Consuetudinário, que é vinculante para todos os Estados, inclusive aqueles que não são partes de um tratado em particular, como é o caso da Declaração Universal dos Direitos Humanos. ${ }^{7}$

Ademais, alguns direitos possuem um status especial como normas imperativas de Direito Internacional Consuetudinário, denominadas jus cogens, que são disposições cogentes, não passíveis de suspensão em qualquer circunstância, além de que assumem primazia, em particular, sobre outras obrigações internacionais, dentre as quais destacam-se, inter alia, a proibição dos atos de tortura, do genocídio, da discriminação racial, bem como da escravidão e práticas análoga. ${ }^{8}$

Em seus votos separados nos casos Massacre de Pueblo Bello vs. Colômbia (OEA, 2006a) e Ximenes Lopes vs. Brasil (OEA, 2006d), o então juiz da Corte Interamericana, Cançado Trindade, expressou seu posicionamento a respeito da necessidade de ampliação do conteúdo do domínio do jus cogens para incluir, ao mesmo, o direito de acesso à justiça.

A indissociabilidade que sustento, entre os artigos 25 e 8 da Convenção Americana, acarreta a caracterização, como sendo do domínio do jus cogens o acesso à justiça entendido como a plena realização da mesma, ou seja, como sendo do domínio do jus cogens a intangibilidade de todas as garantias judiciais no sentido dos artigos 25 e 8 tomados conjuntamente. Não pode haver dúvidas de que as garantias fundamentais, comuns ao Direito Internacional dos Direitos Humanos e ao Direito Internacional Humanitário, têm uma vocação universal a serem aplicadas em todas e quaisquer circunstâncias, formam um direito imperativo (pertencendo ao jus cogens) e acarretam obrigações erga omnes de proteção. ${ }^{9}$

\footnotetext{
Cristina Terezo mostra que alguns doutrinadores, como André de Carvalho Ramos, Diego Rodriguez-Pinzón e Flávia Piovesan, entendem que as Declarações de Direitos Humanos, seja a Universal da ONU ou a Americana, ambas de 1948, teriam força jurídica vinculante por serem utilizadas como fundamento de decisões de Tribunais Internacionais. Ademais, Thomas Buergenthal e Louis B. Sohn defendem que a Declaração é um instrumento formal e solene, cujos princípios e normas teriam sido aprovados por Estados-membros por serem reconhecidamente parte do Direito Internacional Costumeiro. Não obstante, a referida autora ressalva ainda que esta questão não é pacífica na doutrina, na medida em que as Declarações não dispõem de mecanismos de monitoramento, como os outros Tratados de Direitos Humanos, entendidos como convencionais. In: TEREZO, Cristina Figueiredo. Sistema Interamericano de Direitos Humanos: pela defesa dos Direitos Econômicos, Sociais e culturais. Curitiba: Appris, 2014. p. 31.

8 ONU. Organização das Nações Unidas. Escritório do Alto Comissariado para os Direitos Humanos. Protección Jurídica Internacional de los Derechos Humanos Durante los Conflictos Armados. Nova York e Genebra, 2011. HR/PUB/11/01. p. 10. Disponível em: http://www.ohchr.org/Documents/Publications/HR_in_armed_conflict_SP.pdf. Acesso em: 18 out. 2015.

9 "La indisociabilidad que sostengo entre los artículos 25 y 8 de la Convención Americana (supra) conlleva a caracterizar como siendo del dominio del jus cogens el acceso a la justicia entendido como la plena realización de la misma, o sea, como siendo del dominio del jus cogens la intangibilidad de todas las garantías judiciales en el sentido de los artículos 25 y 8 tomados conjuntamente. No puede haber duda de que las garantías fundamentales, comunes al Derecho Internacional de los Derechos Humanos y al Derecho Internacional Humanitario, tienen una vocación universal al aplicarse en todas y cualesquiera circunstancias, conforman un derecho imperativo (perteneciendo al jus cogens), y acarrean obligaciones erga omnes de protección". In: OEA. Organização dos Estados Americanos. CortelDH. Caso Massacre de Pueblo Bello vs. Colômbia. Voto separado do Juiz Antônio Augusto Cançado Trindade. Sentença de 31 de janeiro de 2006a. Série C, N. $140, \S 64$.
} 


\section{Humanos}

Democracia

Esse entendimento mostra-se importante para a proteção internacional dos Direitos Humanos à medida que o artigo $53^{10}$ da Convenção de Viena sobre Direito dos Tratados, define jus cogens como norma imperativa de Direito Internacional geral, a qual é aceita e reconhecida pela comunidade internacional como uma norma da qual nenhuma derrogação é permitida e que somente pode ser modificada por norma de Direito Internacional geral da mesma natureza.

O dispositivo em comento atribui fundamental relevância ao conceito de jus cogens no âmbito do Direito Internacional, haja vista que estas normas peremptórias de Direito Internacional Público impõem uma limitação ao voluntarismo e discricionariedade dos Estados, na medida em que uma norma aceita pela comunidade internacional tem o poder de limitar, anular ou invalidar um acordo entre Estados (AGUIAR; GODOY, 2008, p. 25).

[...] se pretende inculcar é que são regras que estão para além da vontade ou do acordo de vontades dos sujeitos de Direito Internacional; que desempenham uma função eminente no confronto de todos os outros princípios e regras; e que têm uma força jurídica própria, com os inerentes efeitos na subsistência de normas e actos contrários (MIRANDA, 2006, p. 123).

Ao estipular que as normas jus cogens somente podem ser substituídas por outra norma imperativa de Direito Internacional geral, "a Convenção de Viena sobre Direito dos Tratados previu a possibilidade de mudanças dos valores internacionais com a transformação ou evolução da sociedade", de modo que a jurisprudência de uma Corte Internacional pode contribuir com o desenvolvimento da matéria ao pronunciar-se sobre as normativas internacionais referidas (AGUIAR; GODOY, 2008, p. 25), máxime, porque a jurisprudência é fonte auxiliar de Direito Internacional, nos termos do artigo 38. ${ }^{11}$ do Estatuto da Corte Internacional de Justiça.

Desta forma, verifica-se o caráter evolutivo do jus cogens quando as normas que compõem essa categoria não estão previstas em um rol taxativo de algum documento internacional. Trata-se de "uma categoria aberta, que se expande na medida em que se desperta a consciência jurídica universal (fonte material de todo o direito) para a necessidade de proteger os direitos inerentes ao ser humano em qualquer situação". ${ }^{12}$

\footnotetext{
${ }^{10}$ Artigo 53 - Tratado em Conflito com uma Norma Imperativa de Direito Internacional Geral (jus cogens). É nulo um tratado que, no momento de sua conclusão, conflite com uma norma imperativa de Direito Internacional geral. Para os fins da presente Convenção, uma norma imperativa de Direito Internacional geral é uma norma aceita e reconhecida pela comunidade internacional dos Estados como um todo, como norma da qual nenhuma derrogação é permitida e que somente pode ser modificada por norma ulterior de Direito Internacional geral da mesma natureza.

${ }^{11}$ Article 38. 1. The Court, whose function is to decide in accordance with international law such disputes as are submitted to it, shall apply: [...] d. subject to the provisions of Article 59, judicial decisions and the teachings of the most highly qualified publicists of the various nations, as subsidiary means for the determination of rules of law. [...]

12 “[...] es una categoría abierta, que se expande en la medida en que se despierta la conciencia jurídica universal (fuente material de todo el Derecho) para la necesidad de proteger los derechos inherentes a todo ser humano en toda y cualquier situación". In: CorteIDH. Opinião Consultiva OC-18/03, de 17 de setembro de 2003b. Voto concorrente do Juiz Antônio augusto Cançado Trindade. Série A, N. 18, § 68.
} 
Nesse sentido, destaca-se a contribuição da jurisprudência da CorteIDH na identificação de direitos protegidos por normas pertencentes ao domínio do jus cogens, dentre as quais pode-se destacar, inter alia, a proibição ao desaparecimento forçado (OEA, 2006e § 84), princípios da igualdade perante à lei e não discriminação (OEA, 2003a, § 110), bem como proibição à tortura, tratamentos desumanos, cruéis e degradantes (OEA, 2006d).

Especificamente em relação ao direito de acesso à justiça, na sentença do caso Goiburú e outros vs. Paraguai, de 22 de setembro de 2006, a Corte Interamericana declarou que este direito constitui uma norma imperativa de Direito Internacional que gera obrigações erga omnes para os Estados de adotar todas as medidas necessárias, a fim de não permitir a impunidade de violações aos Direitos Humanos. ${ }^{13}$

Esse entendimento jurisprudencial fora ratificado no caso La Cantuta vs. Peru de 2006, no qual a CortelDH, além de declarar que o acesso à justiça integra o domínio do jus cogens, destacou a obrigação dos Estados em combater a impunidade, seja exercendo sua jurisdição em âmbito doméstico, seja colaborando com outros Estados, considerando que o mecanismo de garantia coletiva de Direitos Humanos, estabelecido pela CADH, em conjunto com as obrigações internacionais regionais e universais sobre a matéria, demandam essa cooperação entre os países com o intuito de proteger os Direitos Humanos (OEA, 2006b, § 160).

O reconhecimento do direito de acesso à justiça como norma jus cogens pela CortelDH nos casos supracitados, mostra-se importante no contexto posterior ao período de ditaduras enfrentadas pelos países latino-americanos, na medida em que inúmeros casos de violações sistemáticas de Direitos Humanos, ocorridos nessa época, permaneceram na impunidade, porquanto seus familiares encontram uma série de obstáculos que impedem o devido esclarecimento dos fatos, punição dos responsáveis e reparação dos danos sofridos, em clara denegação de justiça.

Essa atividade jurisprudencial ampliadora do conteúdo material do domínio do jus cogens da Corte Interamericana, igualmente alarga o rol de obrigações erga omnes de proteção para os Estados, cujo cumprimento diz respeito ao interesse da comunidade internacional como um todo, na medida em que se trata de obrigações incondicionais, o que subsidia a ideia do Direito Internacional como "o direito que emana da consciência comum do que é juridicamente necessário (opinio juris communis necessitatis) (TRINDADE, 2001, p. 357).

Diante dessa construção jurisprudencial que consagra o direito de acesso à justiça a partir do vínculo estabelecido entre os artigos 8ㅇ e 25 em relação com os artigos 10.1 e 2으, todos da CADH, Cançado Trindade defende que é importante que os avanços jurisprudenciais a respeito do direito de acesso à justiça lato sensu, alcançados pela CortelDH, sejam preservados e desenvolvidos, contudo que jamais sejam freados com uma hermenêutica desagregadora (OEA, 2006a, § 21).

\footnotetext{
3 "El acceso a la justicia constituye una norma imperativa de Derecho Internacional y, como tal, genera obligaciones erga omnes para los Estados de adoptar las medidas que sean necesarias para no dejar en la impunidad esas violaciones, ya sea ejerciendo su jurisdicción para aplicar su derecho interno y el derecho internacional para juzgar y, en su caso, sancionar a los responsables, o colaborando con otros Estados que lo hagan o procuren hacerlo". In: OEA. Organização dos Estados Americanos. CorteIDH. Caso Goiburú e outros vs. Paraguai. Sentença de Mérito, Reparações e Custas, de 22 de setembro de 2006e. Série C, N. 153, § 131.
} 
É importante que este avanço na jurisprudência da Corte Interamericana seja preservado e desenvolvido ainda mais no futuro. [...] No sistema interamericano de proteção, a jurisprudência sobre a matéria encontra-se em sua infância, e deve continuar a ser cuidadosamente construída. $O$ direito a um recurso efetivo ante os tribunais nacionais competentes no âmbito da proteção judicial (artigos 25 e 8 da Convenção Americana) é muito mais relevante do que até recentemente se supôs, em um continente, como o nosso, marcado por casuísmos que muito frequentemente privam os indivíduos da proteção do Direito. Requer considerável desenvolvimento jurisprudencial nos próximos anos (TRINDADE, 1999, p. 67).

Infere-se, então, que o exercício da jurisdição contenciosa pela CortelDH possibilitou a construção jurisprudencial sólida referente à importância que os direitos às garantias e à proteção judicial representam em uma sociedade democrática, como garantias de proteção do indivíduo ante a eventuais violações de seus direitos, mediante a devida investigação, reparação e punição dos responsáveis por violações aos Direitos Humanos, por meio de recursos céleres e efetivos, que tramitem nos ditames do devido processo legal e atendam aos deveres de respeito e garantia assumidos pelos Estados, quando retificaram a $\mathrm{CADH}$.

Nesse sentido, a proteção conferida pelo direito de acesso à justiça, conforme apontado pela CortelDH (OEA, 2006b, § 160), transcende o próprio voluntarismo e discricionariedade dos Estados, uma vez que não está adstrito às obrigações convencionais, mas a obrigações erga omnes de proteção, contidas em normas imperativas de Direito Internacional Público e inderrogáveis, que somente podem ser modificadas por norma de Direito Internacional da mesma natureza.

\section{CONCLUSÃO}

O direito de acesso à justiça, formado pela união entre os artigos 8 e e 25 da CADH, em relação com os artigos 1‥1 e 2으, deste mesmo tratado, desempenha um papel importante no âmbito da proteção aos Direitos Humanos nas Américas, não apenas pela produção jurisprudencial consolidada a respeito, mas, sobretudo, porque se observa que a violação de outros direitos consagrado na $\mathrm{CADH}$, geralmente, relaciona-se com a denegação de justiça às vítimas, o que contribui para a impunidade e a perpetuação de práticas violatórias.

Percebe-se a fundamental contribuição dos votos em separado do ex-juiz da Corte Interamericana, Cançado Trindade, na construção jurisprudencial pautada em uma interpretação integradora dos dispositivos supracitados, em que pese, desde a sentença de exceções preliminares do caso Velásquez Rodríguez vs. Honduras, o Tribunal Interamericano já se inclinar para uma interpretação correlacionadora entre os artigos 8 e 25 da CADH.

Destaca-se, ademais, que o contexto de violações sistemáticas de Direitos Humanos ocorridas durante os regimes ditatórias nos países americanos, relaciona-se com o reconhecimento, pela CorteIDH, do caráter de norma cogente do direito de acesso à justiça, quando alargou o rol de obrigações erga omnes para os Estados de adotar todas as medidas necessárias, a fim de não permitir a impunidade, empreendendo todas as formas necessárias para remover todos os obstáculos, de qualquer ordem, inclusive legislativa, para que as vítimas ou os seus familiares obtenham o devido esclarecimento dos fatos, punição dos responsáveis e reparação dos danos sofridos. 
Além de contribuir para a proteção dos Direitos Humanos no âmbito do Sistema Interamericano, esse entendimento mostra-se de extrema importância para o Estado brasileiro, haja vista que, apesar da sentença do caso Gomes Lund vs. Brasil de 2010, o Brasil ainda mantém sob o manto da impunidade os agentes que cometeram diversos delitos, inclusive crimes contra a humanidade, com fundamento legal na Lei de Anistia n. 6.683, de 28 de agosto de 1979, a qual já fora declarada inconvencional pela Corte Interamericana.

Assim, segundo a CortelDH, o direito de acesso à justiça é uma norma imperativa de Direito Internacional que gera obrigações erga omnes para os Estados de empreenderem todas as medidas necessárias para garantir a plena realização da justiça para as pessoas sob sua jurisdição, inclusive no que se refere a fatos pretéritos, os quais provocam um sofrimento latente para as vítimas de todas as formas de denegação de justiça.

\section{REFERÊNCIAS}

ADALID, M. M. El Derecho Humano de Acceso a la Justicia. In: ZAMUDIO, H. Liber Americarum. San José: Corte Interamericana de Derechos Humanos; Unión Europea, 1998. p. 1.035-1.049. V. 2.

AGUIAR, A. L. B.; GODOY, G. G. de. Corte Interamericana de Direitos Humanos e a Ampliação do Conteúdo Material do Conceito Normativo de Jus Cogens. Revista do Instituto Brasileiro de Direitos Humanos, Fortaleza, v. 8, n. 8, p. 25-34, 2008. Disponível em: http://www.ibdh.org.br/ibdh/revista_08.asp. Acesso em: 11 dez. 2015.

BLANCO, C. S. T. O Direito de acesso à Justiça nas Jurisprudências Interamericana e brasileira, uma análise comparativa. Revista da Faculdade de Direito da UFMG, Belo Horizonte, n. 61, p. 85-125, jul./dez. 2012. Disponível em: http://www.direito.ufmg.br/revista/index.php/revista/article/view/P.03042340.2012v61p85/221. Acesso em: 15 dez. 2015.

LEDESMA, H. F. El agotamiento de los recursos internos en el sistema interamericano de protección de los derechos humanos. Revista Instituto Interamericano de Derechos Humanos, San José, jul. 2007.

MIRANDA, Jorge. Curso de Direito Internacional Público. 3. ed. Lisboa: Principia, 2006.

OEA. Organização dos Estados Americanos. CortelDH. Caso Almonacid Arellano e outros vs. Chile. Sentença de Exceções Preliminares, Mérito, Reparações e Custas, de 26 de setembro de 2006c.

OEA. Organização dos Estados Americanos. CortelDH. Caso Barrios Altos vs. Peru. Sentença de Mérito, de 14 de março de 2001a.

OEA. Organização dos Estados Americanos. CortelDH. Caso Caballero Delgado y Santana vs. Colômbia. Voto Dissidente do Juiz Antônio Augusto Cançado Trindade. Sentença de Reparações, de 29 de janeiro de 1997a.

OEA. Organização dos Estados Americanos. CortelDH. Caso Cantos vs. Argentina. Sentença de Mérito, Reparações e Custas, de 28 de novembro de 2001b.

OEA. Organização dos Estados Americanos. CorteIDH. Caso Castillo Páez vs. Peru. Sentença de Mérito, de 3 de novembro de 1997c.

OEA. Organização dos Estados Americanos. CortelDH. Caso Castillo Petruzzi e outros vs. Peru. Sentença de Mérito, Reparações e Custas, de 30 de maio de 1999.

OEA. Organização dos Estados Americanos. CortelDH. Caso Durand e Ugarte vs. Peru. Sentença de Mérito, de 16 de agosto de 2000.

OEA. Organização dos Estados Americanos. CortelDH. Caso Gelman vs. Uruguai. Sentença de Mérito e Reparações, de 24 de fevereiro de 2011.

OEA. Organização dos Estados Americanos. CortelDH. Caso Genie Lacayo vs. Nicarágua. Resolução de 13 de setembro de 1997b (Pedido de Revisão da Sentença de Mérito, Reparações e Custas). Voto Dissidente do Juiz Antônio Augusto Cançado Trindade.

OEA. Organização dos Estados Americanos. CortelDH. Caso Genie Lacayo vs. Nicarágua. Sentença de Mérito, Reparações e Custas, de 29 de janeiro de 1997d, Série C, n. 21.

OEA. Organização dos Estados Americanos. CortelDH. Caso Goiburú e outros vs. Paraguai. Sentença de Mérito, Reparações e Custas, de 22 de setembro de 2006 e.

OEA. Organização dos Estados Americanos. CorteIDH. Caso Gomes Lund e outros (Guerrilha do Araguaia) vs. Brasil. Sentença de Exceções Preliminares, Mérito, Reparações e Custas, de 24 de novembro de 2010. 


\section{Humanos}

Democracia

OEA. Organização dos Estados Americanos. CortelDH. Caso La Cantuta vs. Peru. Sentença de Mérito, Reparações e Custas, de 29 de novembro de 2006b.

OEA. Organização dos Estados Americanos. CortelDH. Caso Massacres de El Mozote e Arredores vs. El Salvador. Sentença de Mérito, Reparações e Custas, de 25 de outubro de 2012.

OEA. Organização dos Estados Americanos. CorteIDH. Caso do Massacre de Mapiripán vs. Colômbia. Sentença de Exceções Preliminares, Mérito, Reparações e Custas, de 15 de setembro de 2005.

OEA. Organização dos Estados Americanos. CortelDH. Caso Massacre de Pueblo Bello vs. Colômbia. Sentença de 31 de janeiro de 2006 .

OEA. Organização dos Estados Americanos. CortelDH. Caso Massacre de Pueblo Bello vs. Colômbia. Voto separado do Juiz Antônio Augusto Cançado Trindade. Sentença de 31 de janeiro de $2006 f$.

OEA. Organização dos Estados Americanos. CortelDH. Caso Velásquez Rodríguez vs. Honduras. Sentença de Exceções Preliminares, de 26 de junho de 1987.

OEA. Organização dos Estados Americanos. CortelDH. Caso Velásquez Rodríguez vs. Honduras. Sentença de Mérito, de 29 de julho de 1988.

OEA. Organização dos Estados Americanos. CorteIDH. Caso Ximenes Lopes vs. Brasil. Sentença de Mérito, Reparações e Custas, de 04 de julho de 2006d.

OEA. Organização dos Estados Americanos. CorteIDH. Caso Ximenes Lopes vs. Brasil. Voto separado do Juiz Antônio Augusto Cançado Trindade. Sentença de Mérito, Reparações e Custas, de 4 de julho de 2006g.

OEA. Organização dos Estados Americanos. CortelDH. Opinião Consultiva n. 18/03, de 17 de setembro de 2003a. OEA. Organização dos Estados Americanos. CorteIDH. Opinião Consultiva n. 18/03, de 17 de setembro de 2003b. Voto concorrente do Juiz Antônio Augusto Cançado Trindade.

ONU. Organização das Nações Unidas. Escritório do Alto Comissariado para os Direitos Humanos. Protección Jurídica Internacional de los Derechos Humanos Durante los Conflictos Armados. Nova York e Genebra, 2011. HR/ PUB/11/01. Disponível em: http://www.ohchr.org/Documents/Publications/HR_in_armed_conflict_SP.pdf. Acesso em: 18 out. 2015.

ROBLES, M. E. V. La Jurisprudencia de la Corte Interamericana de Derechos Humanos en Materia de Acceso a la Justicia e Impunidad. Estudios sobre El Sistema Interamericano de Protección de lós Derechos Humanos. San José: Corte Interamericana de Derechos Humanos; Instituto Interamericano de Derechos Humanos, 2007. Disponível em: www.corteidh.or.cr/tablas/r31036.pdf. Acesso em: 15 nov. 2015.

TEREZO, C. F. Sistema Interamericano de Direitos Humanos: pela defesa dos Direitos Econômicos, Sociais e Culturais. Curitiba: Appris, 2014.

TRINDADE, A. A. C. A humanização do Direito Internacional. Belo Horizonte: Del Rey, 2006.

TRINDADE, A. A. C. A proteção internacional dos direitos humanos: fundamentos jurídicos e instrumentos básicos. São Paulo: Saraiva, 1991.

TRINDADE, A. A. C. El Derecho de Acceso a la Justicia Internacional y las Condiciones para su Realización en el Sistema Interamericano de Protección de los Derechos Humanos. Revista del Instituto Interamericano de Derechos Humanos, San José, v. 37, p. 53-83, $2003 a$.

TRINDADE, A. A. C. Hacia la Consolidación de la Capacidad Jurídica Internacional de los Peticionarios en el Sistema Interamericano de Protección de los Derechos Humanos. Revista del Instituto Interamericano de Derechos Humanos, San José, v. 37, p. 13-52, 2003 b.

TRINDADE, A. A. C. Tratado de Direito Internacional. 2. ed. Porto Alegre: SAF Editor, 2001. Tomo I.

TRINDADE, A. A. C. Tratado de Direito Internacional dos Direitos Humanos. Porto Alegre: Fabris, 1999. Tomo II.

TRINDADE, A. A. C. Tratado de Direito Internacional dos Direitos Humanos. Porto Alegre: Fabris, 2002. Tomo III. 